\title{
La enseñanza después de la COVID-19
}

\section{Teaching after COVID-19}

\author{
Mónica A. Cureño-Díaz* \\ Dirección de Investigación y Enseñanza, Hospital Juárez de México, Ciudad de México, México
}

Desde la Antigüedad, la enseñanza de la medicina ha sido por tutoría. Quienes elegimos ser médicos siempre contamos con grandes maestros y maestras durante nuestra formación, y somos afortunados si este acompañamiento perdura posteriormente.

Cuando nos formamos, pensamos que al recibir el título de Medicina casi inmediato recibimos el de maestro o maestra. Si bien el entusiasmo y el compromiso son fundamentales para ser docente, debemos reconocer que la responsabilidad de una vida en tus manos es tan significativa como la de educar o acompañar durante el entrenamiento médico, pues de nosotros dependerán futuros galenos que también tendrán vidas en sus manos a lo largo de su desarrollo profesional.

Como docentes en medicina hemos recorrido las clases presenciales en las aulas, los exámenes frente a la cama del paciente, las prácticas en quirófanos; la evolución de la toma de apuntes desde las notas, las fotocopias, los libros, el subrayado de lo más importante, el resumen, la presentación en acetatos o en Power Point ${ }^{\circledR}$ y hoy para los más jóvenes Keynote ${ }^{\circledR} 0$ Canva ${ }^{\circledR}$ y Kindle ${ }^{\circledR}$; pasando por el aprendizaje por competencias, los cursos en plataformas digitales y cuando pensábamos que lo íbamos dominando jse nos presentó la COVID-19!

$\mathrm{Y}$ encontramos a nuestros aliados, Zoom ${ }^{\circledR}$, Teams $^{\circledR}$, Webex Meetings ${ }^{\circledR}$, pero incluso ante tanta tecnología hemos acordado que siempre se requiere un orientador u orientadora que lleve la guía de cada asignatura, cumpla con el objetivo final y hable de la vida real, a la que pronto han de regresar nuestros estudiantes.

Esta pandemia nos ha enseñando mucho sobre muchos temas, y a los profesionales de la salud nos enseñó que para dar clases necesitamos conocer las tecnologías de la información y las aplicaciones informáticas de dispositivos móviles, tabletas y computadoras para diseñar talleres, compartir pantalla y aplicar evaluaciones; pero también sobre la docencia, porque la educación virtual no es replicar la clase ante una computadora con cámara, debemos cambiar la metodología generando contenido educativo digital y usar la realidad virtual en medicina para ayudar a cumplir las metas de nuestros estudiantes.

Debemos reconocer que los tiempos son distintos, la atención es distinta y los alumnos también son distintos, con otras perspectivas. Y si bien las herramientas virtuales se quedarán como parte de los programas académicos, sigue siendo importante vernos a los ojos y medir el termómetro de la clase, saber si me están entendiendo, si les está gustando, si estoy cumpliendo sus expectativas...

Estoy convencida de que la valiosa tradición de la labor tutorial debe continuar, acompañada de una inevitable evolución de quienes como docentes enfrentamos grandes retos hoy para enseñar en el área de la salud en este mundo globalizado.
Correspondencia:

*Mónica A. Cureño-Díaz

E-mail: dracurenohjm @ gmail.com

1405-9622/৫ 2021 Sociedad Médico-Quirúrgica del Hospital Juárez de México, A.C. Publicado por Permanyer. Este es un artículo open access bajo la licencia CC BY-NC-ND (http://creativecommons.org/licenses/by-nc-nd/4.0/).
Fecha de recepción: 17-04-2021

Fecha de aceptación: 19-04-2021

DOI: 10.24875/RHJM.M21000013
Disponible en internet: 22-06-2021 Rev Hosp Jua Mex. 2021;88(2):44-44

www.revistahospitaljuarez.com 